\title{
Upset Simulation and Training Initiatives for U.S. Navy Commercial Derived Aircraft
}

\author{
Steven Donaldson ${ }^{1}$ \\ Naval Air System Command, Patuxent River NAS, MD 20670 \\ James Priest ${ }^{2}$ \\ Calspan Corp., Buffalo, NY 14225 \\ Kevin Cunningham ${ }^{3}$ and John V.Foster ${ }^{4}$ \\ NASA Langley Research Center, Hampton, VA 23681
}

\begin{abstract}
Militarized versions of commercial platforms are growing in popularity due to many logistical benefits in the form of commercial off-the-shelf (COTS) parts, established production methods, and commonality for different certifications. Commercial data and best practices are often leveraged to reduce procurement and engineering development costs. While the developmental and cost reduction benefits are clear, these militarized aircraft are routinely operated in flight at significantly different conditions and in significantly different manners than for routine commercial flight. Therefore they are at a higher risk of flight envelope exceedance. This risk may lead to departure from controlled flight and/or aircraft loss $^{1}$. Historically, the risk of departure from controlled flight for military aircraft has been mitigated by piloted simulation training and engineering analysis of typical aircraft response. High-agility military aircraft simulation databases are typically developed to include high angles of attack (AoA) and sideslip due to the dynamic nature of their missions and have been developed for many tactical configurations over the previous decades. These aircraft simulations allow for a more thorough understanding of the vehicle flight dynamics characteristics at high AoA and sideslip. In recent years, government sponsored research on transport airplane aerodynamic characteristics at high angles of attack has produced a growing understanding of stall/post-stall behavior. This research along with recent commercial airline training initiatives has resulted in improved understanding of simulatorbased training requirements and simulator model fidelity. ${ }^{2-5}$ In addition, inflight training research over the past decade has produced a database of pilot performance and recurrency metrics $^{6}$. Innovative solutions to aerodynamically model large commercial aircraft for upset conditions such as high AoA, high sideslip, and ballistic damage, as well as capability to accurately account for scaling factors, is necessary to develop realistic engineering and training simulations. Such simulations should significantly reduce the risk of departure from controlled flight, loss of aircraft, and ease the airworthiness certification process. The characteristics of commercial derivative aircraft are exemplified by the P-8A Multi-mission Maritime Aircraft (MMA) aircraft, and the largest benefits of initial investigation are likely to be yielded from this platform. The database produced would also be utilized by flight dynamics engineers as a means to further develop and investigate vehicle flight characteristics as mission tactics evolve through the years ahead. This paper will describe ongoing efforts by the U.S. Navy to develop a methodology for simulation and training for large commercial-derived transport aircraft at unusual attitudes, typically experienced during an aircraft upset. This methodology will be applied to a representative Navy aircraft (P-8A) and utilized to develop a robust simulation that should accurately represent aircraft response in these extremes. Simulation capabilities would then extend to flight dynamics
\end{abstract}

\footnotetext{
${ }^{1}$ Aerospace Engineer, Aeromechanics Division Head, Member AIAA.

${ }^{2}$ Program Manger, Advanced Maneuver \& Upset Recovery Training Project.

${ }^{3}$ Aerospace Technologist, Flight Dynamics Branch, MS 308, AIAA Senior Member.

${ }^{4}$ Aerospace Technologist, Flight Dynamics Branch, MS 308, AIAA Associate Fellow.
} 
analysis and simulation, as well as potential training applications. Recent evaluations of integrated academic, ground-based simulation, and in-flight upset training will be described along with important lessons learned, specific to military requirements.

\section{Nomenclature}

$\begin{array}{ll}\text { AM-URT } & \text { Advanced Maneuver and Upset Recovery Training } \\ \text { AOA } & =\text { angle of attack } \\ \text { AvSP } & =\text { Aviation Safety Program } \\ \text { CBT } & =\text { computer based training } \\ \text { CCS } & =\text { configuration control system } \\ \text { COTS } & =\text { commercial off the shelf } \\ \text { DALM } & =\text { dual-axis load meter } \\ \text { EP } & =\text { evaluation pilot } \\ \text { EUR } & =\text { enhance upset recovery } \\ \text { FPV } & \text { elight path vector } \\ \text { FFS } & \text { full flight simulator } \\ \text { FRTC } & =\text { Flight Research Training Center } \\ \text { GBS } & \text { ground-based simulator } \\ \text { IFD } & =\text { Integration Flight Deck } \\ \text { IFS } & =\text { in-flight simulation } \\ \text { KIAS } & =\text { indicated airspeed, kts } \\ \text { LaRC } & =\text { Langley Research Center } \\ \text { LOC } & =\text { loss of control } \\ \text { MANPADS } & =\text { Man-Portable Air Defense Systems } \\ \text { MMA } & =\text { Multi-mission Maritime Aircraft } \\ \text { MSL } & =\text { mean sea level } \\ \text { NASA } & =\text { National Aeronautics and Space Administration } \\ \text { NAVAIR } & =\text { Naval Air Systems Command } \\ \text { PFD } & =\text { primary flight display } \\ \text { PIO } & =\text { pilot induced oscillation } \\ \text { PLI } & =\text { pitch limit indicator } \\ \text { SBIR } & =\text { Small Business Innovative Research } \\ \text { UAR } & =\text { unusual attitude recovery } \\ \text { UER } & =\text { upset event recovery } \\ \text { t } & =\text { time } \\ & \end{array}$

\section{Introduction}

Militarized versions of commercial platforms are growing in popularity due to many logistical benefits in the form of commercial off-the-shelf (COTS) parts, established production methods, and commonality for different certifications. Commercial data and best practices are often leveraged to reduce procurement and engineering development costs. While the benefits are clear, these militarized aircraft are operated at significantly different conditions and in significantly different manners than their commercial counterparts in flight. Therefore they are at much higher risk of flight envelope exceedance. This risk may lead to departure from controlled flight and/or aircraft loss ${ }^{1}$.

Historically, the risk of departure from controlled flight for military aircraft has been mitigated by piloted simulation training and engineering analysis of typical aircraft response. High-agility military aircraft simulation databases are typically developed to include high angles of attack (AoA) and sideslip due to the dynamic nature of their missions and have been developed for many tactical configurations over the previous decades.

Current FAA certification for commercial aircraft simulators does not include requirements for stall behavior other than stall identification and stall speed matching. No criteria are provided for the lateral/directional axes which are critical to capture important flight characteristics for approach to stall and post-stall conditions. In some cases, lack of aerodynamic data would require considerable extrapolation of wind tunnel data from low AoA and sideslip 
conditions that does not capture the complex aerodynamics and physical phenomena present at extreme attitudes and result in a non-representative simulation at these conditions. The current certification approach has been acceptable for the commercial community and the FAA, due to the assumed low probability of experiencing these conditions during a typical commercial flight profile. The potential for poor modeling accuracy for highly dynamic high AoA maneuvers is compounded by the fact that accounting for scaling factors in large commercial-type aircraft is extremely complex. This results in simulation databases that are inadequate for predicting the aircraft response at near stall or post stall conditions.

In recent years, government sponsored research on transport airplane aerodynamic characteristics at high angles of attack has produced a growing understanding of stall/post-stall behavior. This research along with recent commercial airline training initiatives has resulted in improved understanding of simulator-based training requirements and simulator model fidelity. ${ }^{2-5}$ In addition, in-flight training research over the past decade has produced a database of pilot performance and recurrency metrics ${ }^{6}$.

The flight environment of a military aircraft, in addition to the flight conditions, is also significantly different from that of a commercial aircraft. The military flight environment includes additional considerations and threats such as extreme weather conditions or Man-Portable Air Defense Systems (MANPADS). Current commercial simulations do not have any representation of damage due to ballistic impact, a condition that could also lead to upset conditions and possible aircraft loss due to departure or loss of control. Furthermore, the increased pilot workload associated with military missions and higher threat environments has historically uncovered aircraft deficiencies. Such deficiencies likely have not been discovered in the benign commercial environment. While loss of aircraft has numerous intangible effects, the financial loss of a single aircraft could top $\$ 150 \mathrm{M}$, which would be a significant impact to today's conservative budgets. With high fidelity modeling and simulation of upset conditions, the military operator can properly train to these scenarios significantly enhancing the probability of successful recovery.

Innovative solutions to aerodynamically model large commercial aircraft for upset conditions such as high AoA, high sideslip, and ballistic damage, as well as capability to accurately account for scaling factors, is necessary to develop realistic engineering and training simulations. Such simulations should significantly reduce the risk of departure from controlled flight, loss of aircraft, and ease the airworthiness certification process. The characteristics of commercial derivative aircraft are exemplified by the P-8A Multi-mission Maritime Aircraft (MMA) aircraft, and the largest benefits of initial investigation are likely to be yielded from this platform. The database produced would also be utilized by flight dynamics engineers as a means to further develop and investigate vehicle flight characteristics as mission tactics evolve in the years ahead.

This paper will describe ongoing efforts by the U.S. Navy to develop a methodology for simulation and training for large commercially-derived transport aircraft at unusual attitudes, typically experienced during an aircraft upset. This methodology will be applied to a representative Navy aircraft (P-8A) and utilized to develop a robust simulation that should accurately represent aircraft response in these extremes. Simulation capabilities would then extend to flight dynamics analysis and simulation, as well as potential training applications. Recent evaluations of integrated academic, ground-based simulation, and in-flight upset training will be described along with important lessons learned, specific to military requirements.

\section{Program Approach}

During the early stages of the P-8A development program, much consideration was given on how to employ a Boeing 737 derivative aircraft to perform the anti-submarine warfare mission. Through the P-8A development process, early simulation models of the P-8A in mission-relevant scenarios were exercised to evaluate the best methods to use to execute the P-8A missions. By exercising these early simulation models in mission relevant scenarios, it was also possible to evaluate the margins relative to aircraft limits. With a clearer vision of mission execution and vehicle flight limits, the margins to those limits while executing mission scenarios were not as large as what the pilot community had experienced with P-3 aircraft operations. With this information in hand, the concept of improved pilot awareness and an expanded training regime was felt to be a reasonable path forward for the P-8A. 
With a generalized desire for expanded training capabilities, NAVAIR embarked on developing an approach to fulfill the need but within budget constraints. Because the desired training capabilities didn't firmly exist with the commercial sector that were fully applicable to the P-8A configuration and mission spectrum, the Naval Air Systems Command established an incremental path for developing training capability as well as identifying areas of training improvements as well as aerodynamic data gaps as the training was developed. The initial step was to evaluate the present state of commercially available upset recovery training. The evaluation included the methods of training, the logic and data behind the offered syllabi, the representativeness of the training vehicles' dynamics, and the physical cues and cockpit displays presented to the pilot. Upon completion of the initial step and a thorough evaluation of the current capabilities and gaps, the Navy embarked on a three pronged engineering approach to addressing upset recovery for military application:

1. Leverage research and modeling conducted by NASA Langley Research Center (LaRC) in aircraft Upset Recovery and apply these methods and practices to a Navy aircraft configuration - acquiring improved aerodynamics database fidelity throughout an extended flight envelope, and leveraging the available simulation facilities to determine of the proper set of training capabilities to utilize for an Upset Recovery training curriculum.

2. Develop cost-effective methods of developing enhanced aerodynamic databases

3. Assess the viability of existing Upset Recovery Training for use within the military sector and develop a training curriculum for use within the P-8A community

\section{A. NASA LaRC Aerodynamic Modeling Research}

The aerodynamic model used for this study was based on a research implementation of an existing crew training simulator for a transcontinental jet transport with two wing-mounted engines and a conventional tail. This model was used for research under the NASA Aviation Safety Program (AvSP) and included extensive updates for a highfidelity stall model. The stall aerodynamic model was based on extensive wind tunnel testing using state-of-the-art static and dynamic test methods developed for previous military aircraft programs. The development of the updated stall model was reported in ref. 2 and included validation based on flight test data.

Due to the geometric similarities between the research configuration and the P-8A, a "representative" modeling approach was used to provide simulator fidelity that was considered suitable for the purposes of this study. The objective was for the simulator to represent important stall characteristics, necessary for transfer-of-training skills. The most notable characteristics were as follows;

- Degraded stability and control response with increasing AOA

- Stall buffet

- Un-commanded roll-off during approach to stall

- Pitch break at stall

The mass properties of the existing simulation were replaced with that for the P-8A. However, due to the similarities between the research configuration and P-8A control system, the surface deflections, control feel, and stability augmentation were left unchanged. The stall buffet model was based on existing frequency spectrum data for the research configuration that was triggered as a function of angle of attack. The stall warning system included a production transport airplane stick shaker that was nearly identical to that of the P-8A and was triggered as a function of angle of attack from the stall warning computer. No adjustments for aerodynamic stability or control effectiveness were made.

\section{Comparison to flight test stall data}

Because P-8A flight test stall data was not available at the time of this evaluation, no attempts were made to validate the model other than general qualtitative assessments by Navy pilots. Subsequent to the evaluation, P-8A stall data was provided that allowed a general assessment of the fidelity of the representative P-8A model. Time history comparisons were completed that were based on back-driving the simulator with flight test control inputs with mass properties and flight conditions for that of the flight tests. 
A comparison of the P-8A representative simulation and flight test data is shown in figure 1 for a 1-g stall. These data indicated good correlation in the following areas;

- Elevator and stabilizer deflections for trim conditions

- Pitch and roll control response during the approach to stall and stall recovery

- Un-commanded roll-off during the approach to stall

- General pitch-up tendencies during the approach to stall

It was noted that the flight test data indicated a more abrupt pitch-up tendency than the simulator model. This difference is seen in the figure at $\mathrm{t}=40 \mathrm{sec}$ where the pitch rate response diverges until nose-down control for recovery is applied. Also, correlation with spoiler response due to large wheel deflections indicated the simulator response was greater than the aircraft and this remains an area for further study.

It was concluded that the simulator model was adequate for the purposes of evaluating the general stall behavior and suitability of various maneuvers for the proposed training curriculum. It should be noted that some variations in the time history response were expected due to differences in the configuration that the aerodynamic model was based upon. However, further study is required to determine the significance of behaviors, such as un-commanded pitch-up, and the potential influence on training requirements.
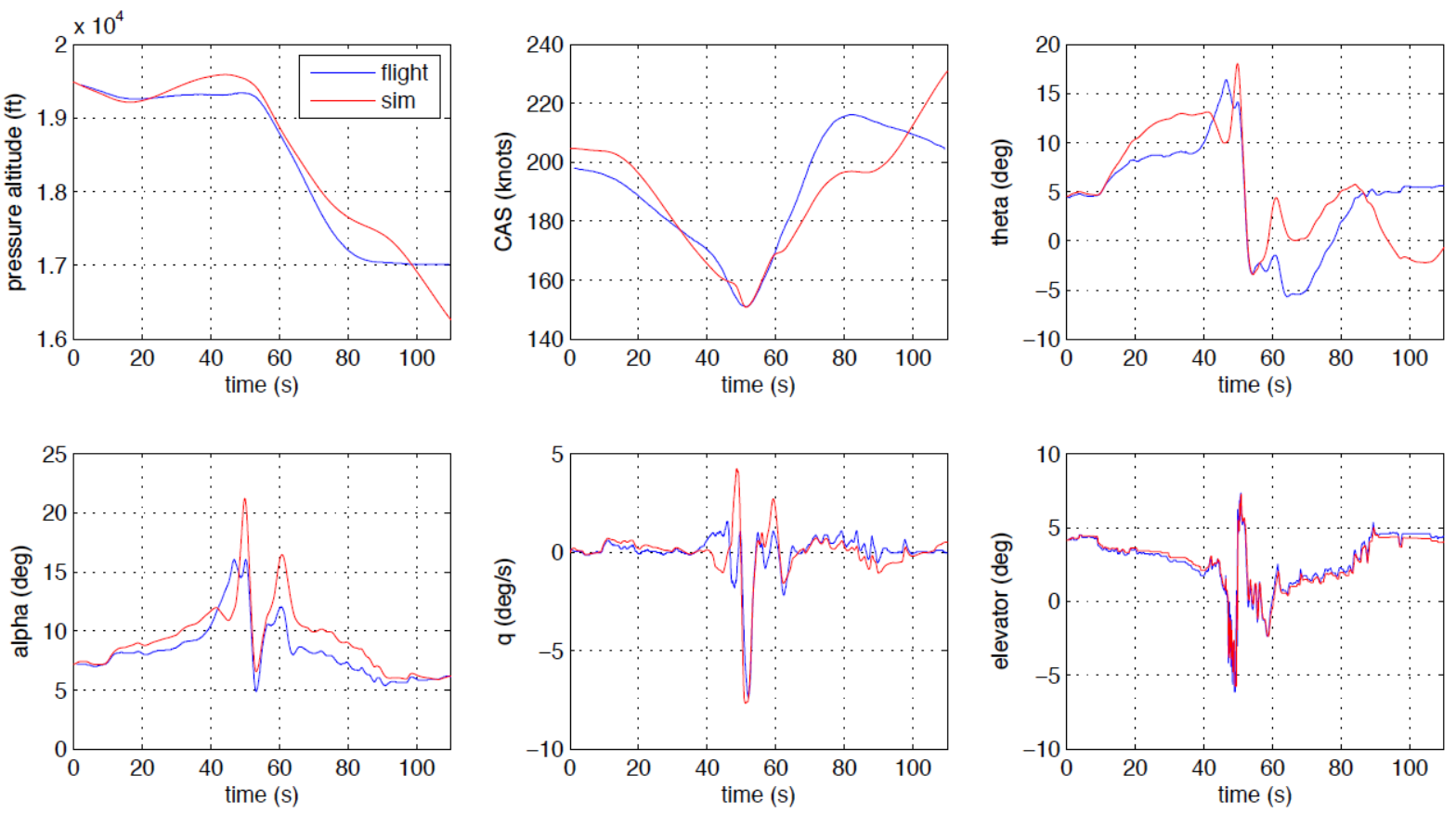

Figure 1. Comparison of representative model with P-8A flight data.

\section{B. Cost-effective methods of developing enhanced aerodynamic databases}

In order to reduce costs for collecting high AOA and sideslip aerodynamics data, the US Navy sponsored a Small Business Innovative Research (SBIR) project entitled Innovative Techniques of Modeling and Simulation for Commercial Derivative Aircraft Upset Recovery (ref. 1). The intent of the project was to provide innovative low cost solutions for the development of a robust aerodynamic database. Recognizing the limitations that existed in commercial models relative to flight conditions that may be encounted during an upset recovery event, - generally high AoA and sideslip, the SBIR set forth to develop a higher AoA and sideslip aerodynamic database as well as inclusion of dynamic effects. The configuration chosen to test was a P-8A -like configuration. Results of this activity are reported in ref. 6 and a synopsis of the effort is as follows: 


\section{Model Description}

A 1/16-scale model representative of a P-8A aircraft was designed and manufactured for low-speed static and dynamic testing with the desire to achieve the highest possible Re through increased model scale and test speed. The model incorporated replaceable leading and trailing edge wing surfaces for the various inboard/outboard slat and flap deflections, flap track fairings, nacelles \& pylons, horizontal tail with variable stab incidence and adjustable elevator, and vertical tail with adjustable rudder.

\section{Test Rig Development}

Since none of the test facilities examined had adequate dynamic test apparatus for the type of testing required, the design and fabrication of large scale dynamic test data suitable for this type of test was required. The rig needed to have sufficient mechanical strength to eliminate any deflection under the anticipated test loads, both statically and in dynamic motion at high dynamic pressure (up to a dynamic pressure of at least $15 \mathrm{psf}$ ) for a large-scale transport aircraft at high angles of attack and sideslip. The balance interface needed to be easily configurable for whatever balance ultimately suited the test requirements. Finally, the late recognition of the need to use the rig for the acquisition of high angle of attack static data (given the unreliable availability of test rigs with suitable capabilities in the candidate facilities) further complicated the design requirements.

Following a rigorous review of facilities, model sizes, weights, inertias and test conditions (both static and dynamic), a number of design features were established. The final configuration would have a multi-piece pedestal mount to provide the greatest facility flexibility. The final test rig design also uses COTS motion control hardware and software to provide a precision multi axis motion capability, that when combined with the turntable rotation axis, would allow the rig to achieve an extensive angle of attack and sideslip envelope.

\section{Data Acquisition Software Development}

The data acquisition and rig control software forms a key component of a successful, functional test apparatus. The data acquisition and control system is composed of several elements. These elements begin with the actual sampling of the analog balance signals, position encoders, tunnel conditions, etc., and conversion of these to a correlated digital time sequence. Once the data is acquired, numerous automatic operations must take place, including filtering consistent with the test motion and tares, removal of the tare data, and for dynamic data, extraction of the forces and moments at the appropriate point in the motion time history. The software must also provide the user an interface to set up, control, and visualize the resulting data. The software must provide an interface, communication and hardware drivers for controlling the operation of the various hardware components, in the serial form in which the test is conducted. And finally, the software must record the tested results.

\section{Wind Tunnel Test Results}

The wind tunnel tests examined the P-8A-like configuration over a large range of angles of attack and sideslip for static and dynamic test conditions. These experimental results were compared to predicted aerodynamic characteristics.

Experimentally derived aerodynamic characteristics were generally in good agreement with the existing simulation database at low angles of attack. Data comparisons were made only for Flap=0. Differences are observed in the static lift and pitching moment characteristics, particularly max lift values, stall angle and region of relatively flat pitching moment, as expected due to the lower test Reynolds number. Significant differences are also observed for the pitch damping derivative values at high angles of attack, where predicted characteristics are suspect and quickly reduce to essentially zero in the post-stall region.

Because differences exist between predicted and actual flight, analysis and extrapolation of aerodynamic coefficients can only be performed with great care and caution. Through simulation, the expanded aerodynamics database generated from the wind tunnel may be exercised to evaluate the aircraft beyond the tested flight envelope in a variety of flight conditions and operational states - with and without failure modes. 


\section{Training Methods and Syllabus Development}

In order to develop a training syllabus for an upset recovery curriculum for military application, it was first necessary to define training objectives. An obvious step was to examine the existing commercial sector practices and apply appropriate modifications to fulfill differences that may exist due to the military missions. For the first step in evaluating commercially available practices, the Navy sponsored a study in through Calspan Corporation to develop a training curriculum for a P-8A-like configuration. Navy line pilots and test pilots alike were exposed to the curriculum. Upon completion of one study, the curriculum and facilities were modified as enhanced aircraft models and tools matured. The result has been acceptance within the Navy pilot community of a solid set of objectives, clear instruction for enhanced understanding and comprehension, and more robust aerodynamic databases that accurately represents the dynamics of the aircraft.

The curriculum developed included academics comprised of computer based training and classroom lecture of basic aerodynamics, the forces and moments acting on a vehicle, vector relationships, axes coupling, effects of gravity and case studies of actual aircraft upset events. A ground-based simulator as described below was utilized for training of flight charactertics leading up to loss of control as well as for training of recovery strategies in upset conditions and lastly in-flight simulation in the variable stability Calspan Learjet.

\section{Academics}

The academics consisted of a Computer Based Training (CBT) module and live-taught classroom instruction. The CBT was developed by a third-party vendor. It was based on content supplied by Calspan to meet the training objective as an introductory module to introduce terms and concepts and provide the pilots with some familiarity. The vendor worked with Subject Matter Experts (SME) from Calspan to build storyboards prior to being turned into courseware. Draft training modules were incrementally delivered to the SME throughout the process to ensure they met requirements. Final courseware was delivered as a stand-alone package that was hosted on the Calspan website in a password protected eLearning format. The courseware developed was Level 2 (intricate animations, simple interactions where required, embedded testing). The courseware contained an exam at the end with ten questions drawn from a bank of twenty possible questions. Additionally, simple knowledge checks were included in the content as important concepts are covered. Content was developed with US Navy interface colors and logos with a focus on the P-8A to include renderings used to demonstrate the concepts.

For the classroom instruction, training materials consisted of PowerPoint slides with embedded videos and a companion reference manual. The academic content developed during the previous study was used as a baseline. It was further developed with content related specifically to and associated with the P-8A aircraft and mission. For example, the materials relating to aircraft loads and limits were tailored specifically to the P-8A envelope (as compared to a typical transport category B737). Relevant aspects of the pilot interaction with automation as it relates to both upset causal factors and recovery strategies were also included. The pilots were given instruction in advanced aerodynamics, causes of jet upset, and introduced to the critical skill-sets necessary for recovery. Finally, the training content was expanded to address specific operational issues and concerns solicited from the test and training personnel who previously attended the program. An outline of the topics included in the syllabus are listed in Table 1. 
Table 1. Academics Topics

\begin{tabular}{ll}
\hline \multicolumn{1}{c}{ Section } & \multicolumn{1}{c}{ Topics } \\
\hline Aerodynamic Principles & $\begin{array}{l}\text { Dihedral Effect, Adverse Yaw, Envelope (Speed vs. g), Corner Speed, Dutch } \\
\text { Roll, Crossover Speed, }\end{array}$ \\
Aircraft Control \& Maneuvering & $\begin{array}{l}\text { Primary and Secondary Controls, Control of Flight Path, Pilot Induced } \\
\text { Oscillation (PIO), Stall/Shaker recovery }\end{array}$ \\
Aircraft Stability & $\begin{array}{l}\text { Aerodynamic Center, Effect of CG Shift on aircraft response, specialized control } \\
\text { technique for unstable aircraft }\end{array}$ \\
Aero Loads & Rolling g's, Effect of Rudder on Tail Loads \\
Causes of Upsets & Pitch Axis, Roll Axis, Yaw Axis, Disturbances \\
Unusual Attitude Recovery & Nose High, Nose Low, Close to Terrain \\
Upset Recovery & Alternate Control Strategy, Measured Response \\
\hline
\end{tabular}

\section{Flight}

In-Flight Simulation (IFS) aircraft are unique in that they can be made to replicate the characteristics of other aircraft using custom built on-board computers and related hardware (Figure 2). Similar to ground-based simulation, the IFS computers are programmed with data for the airplane to be simulated. The computers then control the IFS aircraft so that it reproduces the handling characteristics of the aircraft to be simulated. IFS is also limited by the accuracy of the aerodynamic data. However, beyond the constraints of the aerodynamic data, IFS reverts to the baseline airplane characteristics. In contrast, ground based simulators revert to either extrapolated data or "hold last value”, neither of which is likely to be representative of the actual aircraft characteristics.

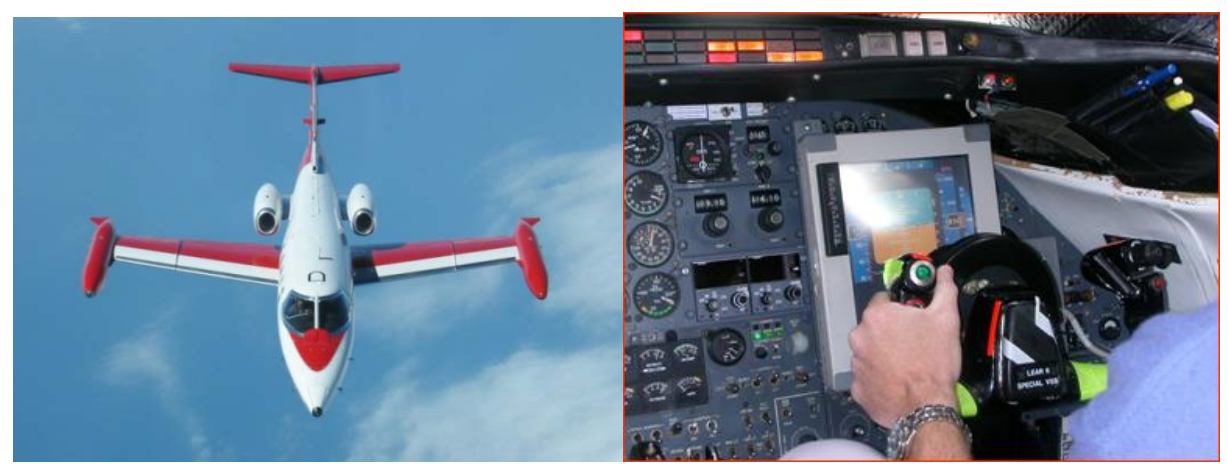

Figure 2. - In-Flight Simulation Aircraft and Pilot Station.

The IFS training consisted of a demonstration of the aerodynamic concepts discussed in academics, recovery from extreme aircraft attitudes, jet upset recoveries, and techniques to ascertain and evaluate the extent of aircraft damage as it relates to controllability and ultimately the ability to land. Development of the IFS profile consisted of the rehosting and checkout of the representative P-8A-like model used in the previous study and verification of the maneuvers. In addition, further refinement of the stall characteristics in the cruise configuration was made in an effort to improve the fidelity of the simulation. The simulation exhibited representative characteristics throughout the envelope (200-300 KIAS) in cruise and in the approach to stall regime for the shaker-recovery demo (150-175 KIAS). The Primary Flight Display (PFD) was the standard Honeywell format with Flight Path Vector (FPV) and key indicators necessary to represent approach to stall to include the Pitch Limit Indicator (PLI) and yellow/red 
hatching and bar on the airspeed tape. In addition, the P-8A style analog-digital g-meter was added to the PFD in the upper right hand corner of the display (same location as on P-8A PFD). Figure 3 below illustrates format and placement.

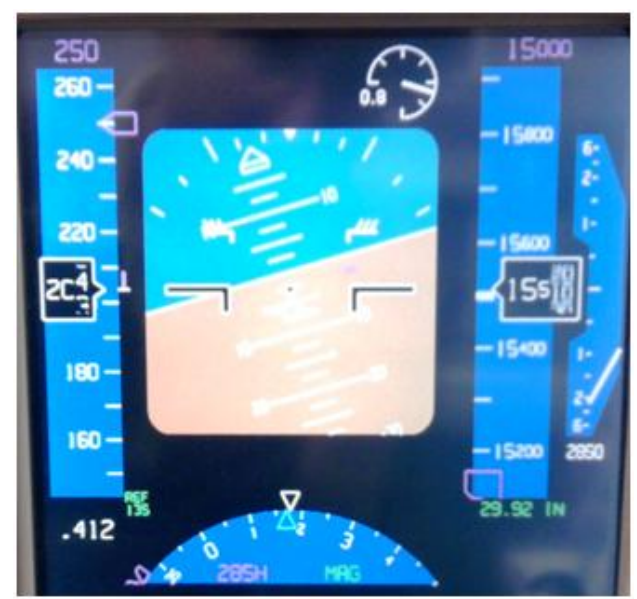

Figure 3. IFS Aircraft PFD.

Upset events programmed into the IFS system were actuated by a control column mounted switch or through the Configuration Control System (CCS) interface. Magnitude of the events was selectable from 0 (no input) to 10 (maximum input). The auto-recovery capability that returns the Learjet from any upset condition to a straight and level attitude by pressing the green button on the Evaluation Pilot (EP) column and the autopilot that holds altitude and tracks heading to allow training related to automation issues were also implemented. Finally, the Unusual Attitude Recovery (UAR) auto-setup feature that back-drives the controls to facilitate repeatable initial conditions for UAR training was implemented. Unless otherwise noted, initial conditions for these maneuvers were 15,000 MSL and 250 KIAS. The specific configurations in the profile were as follows:

a. Pitch Stability Demo - The aircraft Center of Gravity (CG) is slewed to various points both within and outside the normal limits. CG positions used are: nominal mid-point, forward limit, aft limit, and just aft of the neutral point (outside normal limits). At each CG position, the flying qualities of the airplane were sampled by the pilot.

b. Roll Stability Demo - Capture bank angles using small and large roll inputs. Evaluated how roll characteristics change with input magnitude and control technique.

c. Dutch Roll Stability Demo - Dutch Roll was initiated by automatic rudder doublet in a parallel manner (no rudder pedal deflection by EP). Size was selectable in order to account for pilot skill and proficiency. This demonstration was implemented to be functional with model yaw damper on and off.

d. PIO Prone Aircraft Demo - A PIO prone aircraft was implemented using time-delay. Pilot performed pitch capture tasks with tight control tolerances in order to trigger a PIO. Pilot practiced techniques to exit from the PIO.

e. $\quad$ Nose High Recovery - The aircraft was maneuvered to a given nose-high and banked attitude automatically using the UAR auto-setup capability. The maneuver commenced at 280 KIAS and ended at the desired UAR initial condition: $+30^{\circ}$ pitch, $45^{\circ}$ bank.

f. Nose Low Recovery - The aircraft was maneuvered to a given nose-low and banked attitude by the pilot or the UAR auto-setup capability. For auto-setup, the maneuver commenced at 230 KIAS and ended at the desired UAR initial condition: $-15^{\circ}$ pitch, $90^{\circ}$ bank.

g. Pitch Upset - The trim was set to "runaway" at a normal rate and magnitude was sufficient to exceed the elevator authority. When upset was input, no change in control wheel position occurred. Pilot used both pitch and bank inputs to recover. Backup trim was available. 
h. Roll Upset - A generic roll moment was input of various magnitudes up to and exceeding the authority of ailerons. When upset was input, no change in control wheel position occurred. Pilot used roll input and rudder as necessary as part of an alternate control strategy to recover.

i. $\quad$ Yaw Upset - A generic yaw moment simulating a rudder hardover of various magnitudes was input. When upset occurred, there was no change in rudder pedal position. Rudder input had no effect. Pilot had to use roll input and unload in pitch as necessary as part of an alternate control strategy to recover.

j. Wake Turbulence - A time variant roll disturbance was input to simulate the effect of a wake vortex encounter. Since these moments were inserted as disturbances and summed with the other parameters, the flight controls were still effective during the maneuver. Pilot used roll input and rudder as necessary as part of an alternate control strategy to recover.

k. Stall Departure Demo - Stall characteristics were demonstrated to the extent feasible with Lear simulation capabilities (no direct lift or side force control) and within Lear envelope. Pilot slowed to shaker and recovered. Pitch Limit Indicator and airspeed tape were used for reference. Characteristics simulated included reduction in yaw stability, g-break, and roll-off. (Note: these stall characteristics were simulated as the Learjet remained well above the actual Lear stall speed throughout the demonstration.)

l. Marginally Controllable Aircraft - Cruise - The pitch, roll, and yaw channels were rendered ineffective simulating a total hydraulic failure. Pitch trim was available for control. Pilot used both symmetric and differential thrust and trim as part of an alternate control strategy. Thrust vector was representative of P-8A engine position.

m. Marginally Controllable Aircraft - Approach - The pitch, roll, and yaw channels were rendered ineffective simulating a total hydraulic failure in a boosted airplane. Pitch trim was available for control. Pilot used both symmetric and differential thrust and trim as part of an alternate control strategy. A visual approach is flown to a go-around.

\section{NASA Ground Based Simulator}

The simulation model used in this operational evaluation study is a research implementation of a crew training simulation that represents a transcontinental-range transport airplane with two engines mounted under the wings and having a conventional horizontal tail. The six-degree-of-freedom simulation is a rigid-body model with quasi-static aeroelastic effects and Reynolds number scaling effects. Structural modes are not treated as independent states; rather, aeroelastic effects are accounted for by a series of dynamic pressure-based corrections that are applied to the rigid-body aerodynamic model. Reynolds number effects are incorporated directly into the aerodynamic database. The original crew training flight dynamics model was enhanced based on wind tunnel measurements to accurately represent the flight dynamic characteristic of a transport airplane at stall and post-stall flight conditions. This simulation model is described in detail in references [2-5].

In addition to the representative modeling changes that were previously discussed, several modifications were made to make the GBS PFD more representative of the P-8A PFD. The modifications included the addition of a analog-digital load factor indicator (fig. 4) and changes to the stall warning computer model. The purpose of the changes to the stall warning computer model was to better represent the behavior of the P-8A pitch limit indicator. That change was considered to be particularly important because the pitch limit indicator provides the pilot with a graphical depiction indicating angle-of-attack margin to stall warning onset. 


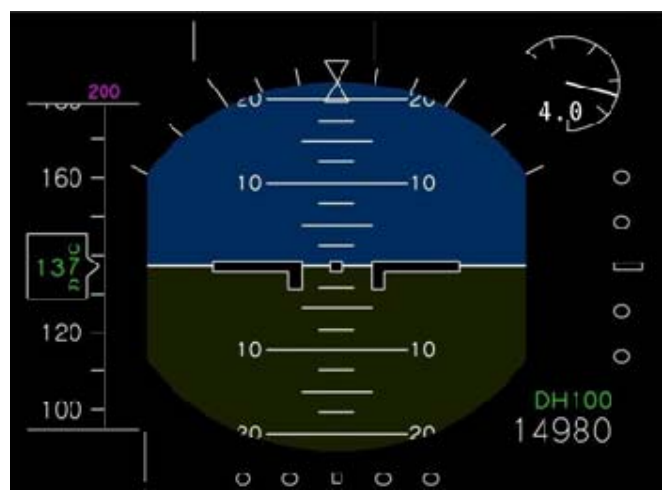

Figure 4. NASA LaRC GBS PFD.

The real-time, pilot-in-the-loop operational evaluation ground based simulator sessions were conducted in NASA Langley's Cockpit Motion Facility Integration Flight Deck (IFD) cockpit (fig. 5). Although not an exact replica, the simulator cockpit is representative of the airplane cockpit that was being simulated. The cockpit has a wide field of view visual system and was operated on a state-of-the-art hexapod motion base. The motion algorithm was modified for this evaluation to provide enhanced stall buffet cueing and continuous very light turbulence superimposed on the normal motion cues. The purpose of the continuous very light turbulence was to enhance realism.

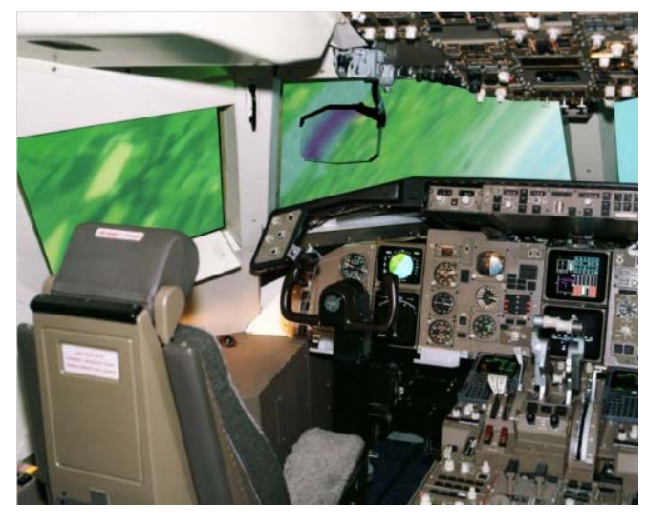

Figure 5. NASA LaRC GBS Cockpit.

Figure 6 shows several elements of a research display in the GBS cockpit. This display was used as a tool to debrief maneuvers for both the evaluation pilot who just flew the maneuver and any other pilots observing at the remotely located instructor operating station. The display, which updates in real time, depicts control inceptor displacements and the angle of attack/angle of sideslip $(\alpha / \beta)$ trajectory which was flown during the maneuver. This $\alpha / \beta$ trajectory was displayed relative to an envelope (shown in green) that depicts a typical training simulator validation envelope. 


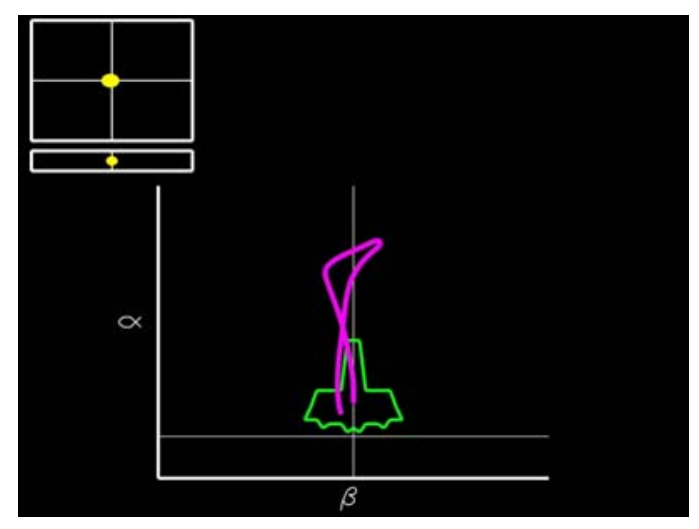

Figure 6. NASA LaRC GBS Alpha-Beta Display.

The GBS cockpit was also equipped with a Calspan Dual-Axis Load Meter (DALM) that was mounted to the glare shield. This 5" x 4" display provided a graphical depiction of estimations for normal force, tail loads, and rolling wing loads. It was used to provide awareness for the potential to develop excessive structural loads if improper control inputs are made.

The GBS sessions and maneuver profiles were designed by NASA, Calspan, and Navy subject matter experts. The goal of the sessions was to evaluate candidate training profiles in a manner that synergistically complimented the IFS sessions. Each session included 1 familiarization profile and 12 candidate training profiles. The profiles to be flown during the simulator runs were specified using a set of 13 test cards (maneuver scripts). Each simulation run began after the simulator was initialized to a trimmed flight condition. This approach eliminated the need for the pilot to spend time maneuvering or climbing to attain the target initial condition. Typically, it took 1 hour to complete one simulation session. In each session one pilot was flying the profiles in the cockpit while a second pilot was monitoring audio and cockpit displays at a simulation operator's station located in an adjacent control room.

The GBS maneuver profile test cards each specified initial conditions, step by step procedures for maneuver execution, and the learning objectives of the profile. A NASA researcher in the cockpit briefed the profile procedures and reviewed the profile objectives after each maneuver. The set of 13 test cards can be broken down into 5 blocks:

\section{Simulator Familiarization \\ 2. Basic Stability and Control Concepts \\ 3. Stalls \\ 4. Unusual Attitudes \\ 5. Alternate Control Strategies}

Test profiles were executed in a sequence that allowed the pilot to build simulator experience with familiarization and basic flight maneuvers before progressing to more advanced maneuvers. Unless otherwise noted, initial conditions for these maneuvers were 10,000 MSL and 220 KIAS. The profiles are summarized below:

a. Simulation Familiarization - This profile provided time to allow the pilot to become familiar with the simulator, particularly the PFD and the characteristics of the flight controls force feel system. This was accomplished by having the pilot fly a profile that consisted of a standard takeoff, climb, g-captures, level-off, turns, and then decelerate to trimmed level flight at 10,000 feet and 220 knots.

b. Roll Stability Demo - This profile required the pilot to capture bank angles using small and large roll inputs. The pilot evaluated how roll characteristics change with input magnitude and control technique. This was repeated using rudder to control bank angle. These characteristics were compared to those seen in the stall demo. This profile demonstrated the basics of roll stability and control. 
c. Pitch Stability Demo - The CG was slewed to various points both inside and outside the normal CG limits. A nominal CG location and one aft of the neutral point (outside normal limits) were simulated. At each CG location, the handling qualities of the airplane were evaluated by the pilot. Degradation of static pitch stability was demonstrated with this profile.

d. Dutch Roll Stability Demo - The Dutch Roll mode was excited from the instructor operation station using a rudder doublet command. The pilot observed dynamic characteristics and practiced damping the Dutch roll. Next, a wings-level sideslip was initiated by the pilot until one red bar appeared on the DALM. The instructor then commanded an abrupt rudder reversal. The pilot simultaneously observed the resulting increased vertical tail structural load condition on the DALM. The potential to overstress the vertical tail with abrupt, inappropriate control inputs was demonstrated with this profile.

e. Stall Departure Demo - The evaluation pilot performed a series of stall related maneuvers. They included recovery at stick-shaker onset, recovery at stall recognition, and recovery from extreme post-stall (loss of control) flight conditions. Buffet cues, stability variation, control effectiveness, thrust effects, and consequences of delayed stall recovery were all demonstrated during this series.

f. Nose High Recovery - The aircraft was maneuvered to a nose-high, low-speed flight condition from which recovery was initiated. The maneuver was repeated with variation in recovery technique to demonstrate the effect of thrust and bank angle on the recovery technique.

g. Nose Low Recovery - The aircraft was maneuvered to a 10 deg nose-low and 90 deg banked attitude. To avoid rolling-g's during recovery, the DALM was monitored while the pilot recovered from this condition. This profile demonstrated the importance of avoiding loaded rolling recoveries.

h. Pitch Upset - A "runaway" stabilizer was simulated. The simulation moved the stabilizer at normal rate to the aircraft nose up trim stabilizer hard stop. The pilot used pitch, bank, and thrust inputs to recover and maneuver the simulator. This profile demonstrated an alternate pitch control strategy.

i. Roll Upset - Full uncommanded deflection of left aileron and all left side spoilers was simulated. When the upset was input, no change in control wheel position occurred. The pilot used roll input to arrest the roll rate and used rudder as necessary to recover back to a wings level flight condition. The DALM was monitored to ensure rudder inputs were smooth and measured. This profile demonstrated an alternate roll control strategy.

j. Yaw Upset - Hardover of rudder power control units were simulated. When this occurred, there was no change in rudder pedal position. Rudder input alone was not sufficient to recover. To recover, the pilot had to use roll input and unload in pitch as necessary. This profile demonstrated an alternate yaw/roll control strategy.

k. High Altitude Shaker Recovery - This maneuver was initiated at 40,000 MSL and 0.76M. The pilot slowed the aircraft to onset of stick shaker and attempted recovery by adding thrust while maintaining altitude. Once the pilot saw that the use of thrust alone was insufficient for recovery, the pitch attitude was reduced to exchange altitude for airspeed. This profile demonstrated high altitude thrust limitation, high altitude maneuver limitations, and high altitude decreases in stall angle of attack margins.

1. Low Altitude Accelerated Stall - This maneuver was initiated at 1,000 AGL and 220 KIAS. An auto-throttle failure was simulated by reducing the power to idle as the pilot was instructed to attain an over-banked $\left(60^{\circ}\right)$ condition. The pilot was then instructed to pull into a stall, simulating potential consequences of distraction, etc. The pilot initiated recovery at the onset of buffet by unloading, rolling wings-level, and adding maximum thrust.

m. Marginally Controllable Aircraft - Approach - The loss of all hydraulic fluid was simulated. The pilot used both symmetric and differential thrust as part of an alternate control strategy to control the airplane. A visual approach was flown to a go-around. This profile demonstrated the use of thrust as a means for alternate flight control.

\section{Training Assessment and Results}

\section{A. Pilot comments}


Participant pilot ratings (high/low) for the four elements of the training program are shown in Figure 7. Both the CBT and classroom instruction had the lowest low scores of "Good" (3). But, pilot comments were positive for both. For the CBT, comments ranged from "most needed" to "CBT and classroom meshed nicely". Both flight training devices were scored at least "Very Good" (4). In comparing the hexapod simulator to the IFS aircraft, pilots commented - "aircraft was the best training I've ever had on this subject" and "scored the ground sim "very good" only because the aircraft was a better tool". Overall, the course was rated "Very Good" (4) to "Excellent" (5). Pilot comments included - "very good training" and "much improved from both NASA and Calspan inputs from past training I’ve received"

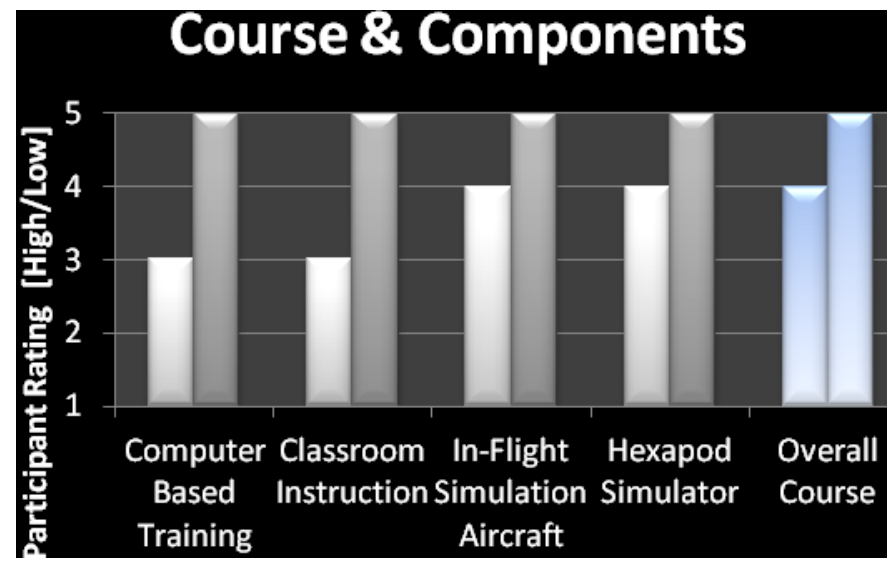

Figure 7. Overall Participant Pilot Scores.

Participant pilot scores (Mean \pm Standard Deviation) for the four elements of the training program are shown in Figure 8. Average score and variance was highest for the CBT. This was largely due to the degree to which an individual pilot views varied for such training. Comments supported this - "hard to learn from a computer" and "questions I had after completing the CBT were answered in the brief" All pilots viewed the classroom instruction to be necessary and valuable to prepare for the flight training. Variability in scores was due primarily to disagreement in how long the class should be and what level of detail was appropriate. Both flight training devices were scored high and both were deemed to be important to the overall value of the training.

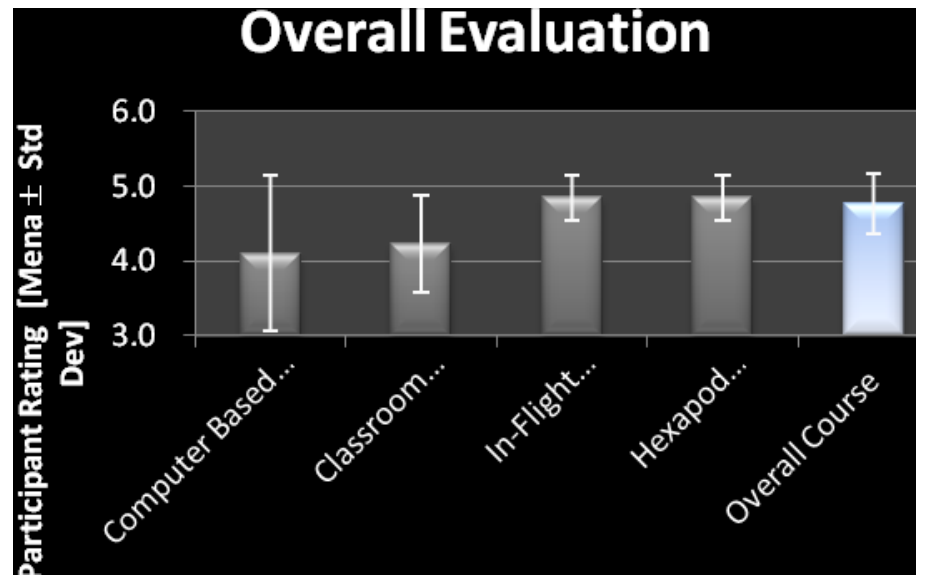

Figure 8. Overall Participant Pilot Scores (maximum score $=5$ ).

Three specific questions were asked following the ratings to solicit comment as follows:

1. What do you think was the most valuable part of the training and why?

2. What would you change and what else would you emphasize? Why? 


\section{Please circle which event occurred first (Simulator, Learjet). Which would you choose to be first and why?}

Responses to the questions with related discussion are provided below. GBS/IFS in square brackets indicates the event that occurred first in this study. Note that participants used the words "sim" or "simulator" to identify the GBS and words "jet", "aircraft", "plane”, or "Lear" to identify the IFS.

For question $\# 1$, the majority of the responses indicated the pilots viewed the IFS training to be the most valuable part of the program. Second was the GBS and in particular, the stall training events. There was no bias in responses due to which flight training event occurred first

[GBS] "Stall recovery and AOA discussion."

[GBS] "CG training... getting to see actual stall in the Sim... alternate methods of control in the aircraft."

[GBS] "The flight... feeling the forces acting on the aircraft and feeling the g's is invaluable"

[GBS] "The flight... it pulled the whole program together"

[GBS] "The flight... it opens the aperture for pilots on some very non-intuitive events"

[GBS] "I really like how it builds from classroom, to sim, to flight... the entire training together is most valuable... classroom is important but, must see it and execute recoveries in sim and Learjet to get the most out of it."

[IFS] "By far the flight was the most valuable... to be able to do these things in an aircraft is superb.

[GBS] "The NASA sim is a great instructional training, particularly for student induce errors"

[IFS] "Stall series in the sim and upset recovery in the airplane... stall series is much needed."

[IFS] "Depth of classroom instruction perfect... spent more time applying techniques and seeing different predicaments rather than dissecting in a classroom environment... keep current ratio of instruction to application.”

[IFS] "Each part was important... if one were taken out, then the other two would suffer... also, a one page summary of what the course covers would have been very useful... we came into the training with very little understanding of what was expected."

[IFS] "Getting a look at less severe versions of the upset events (build up) was really helpful towards solidifying your understanding of how your alternate control inputs can be used to both help and hurt your situation".

For question \#2, pilots cited the need to make training more specific to the P-8A aircraft and mission. There was a desire to accomplish more training in the low/high altitude regime and to take the scenarios to landing in the GBS. There was no bias in responses due to which flight training event occurred first

[GBS] "Moving forward, I would make more specific P-8 comparisons and tailor the training to what a Navy pilot already has received"

[GBS] "I would incorporate some more mission representative profiles particularly high altitude maneuvering and low altitude automation failures (i.e. auto-throttle off, delta-P fails, etc)."

[GBS] "In the Sim, we have the opportunity to take these to landing... the upset recoveries need to be taken to landing... in a steady state training program, it would be necessary to give the scenario with the upset and malfunction... good for crew coordination and thinking through the entire problem solving process and confidence building."

[GBS] "No changes... I would just recommend it to all future P-8A pilots... I believe P-8A pilots will find themselves in certain of these situations in the very near future."

[IFS] "I would incorporate low altitude predicaments into the simulator to try and replicate future P-8A operating environment... only area where I see the need for improvement."

[IFS] "I wouldn't remove anything but, add more low altitude recovery training... most of the P-8A flying will be low altitude flying (less than 1,000 AGL) over the ocean so more training at those altitudes in the sim and in the classroom would be very beneficial."

[IFS] "In the sim, let one of the malfunctions play out to landing".

[IFS] "Need better g-forces in the sim."

[IFS] "Use the sim to a full scenario capability... I know it requires more time but I would love to take a few of the upset conditions all the way to an approach and landing."

For question three, responses indicate that both flight training events are viewed to be important. However, there does not appear to be a consensus as to the ordering of the events. This may be affected by which event occurred 
first. The views of participants who did GBS first had a greater tendency to choose that as the first event whereas those who did the IFS first tended to have little or no preference. Those who chose GBS first cited things like the value of practice and preparation and the more controlled environment of the GBS. Those who chose the IFS first cited the value of realism and setting appropriate expectations. Selected comments below provide insight.

[GBS] "always simulate first... it allowed me to make mistakes in a safe place and do better in the jet"

[GBS] "the sim, most definitely"

[GBS] "simulator is a build up"

[GBS] "Sim I guess... see it in the sim then practice it in the plane... I do think either one first is okay."

[GBS] "I would recommend simulator first because the traffic complications and airspace constraints marginally detract on first exposure".

[GBS] "The Sim is not real... so doing the Learjet first you have an expectation for how things are supposed to feel... in the sim, the accelerations are not as large".

[IFS] "Given the choice, I know I would always choose to practice these events in the sim first to maximize my time flying the aircraft... but, I think the training was great in both venues either way."

[IFS] "Probably the simulator... the sim is a much more controlled environment and is more relaxed... the Learjet flight had multiple aircraft to watch out for and that caused a few interruptions... the flight was great but, the sim was easier to learn all of the concepts we learned in the classroom."

[IFS] "The order in which they occur did not matter... the flight and the sim in close combination (day apart) is what matters."

[IFS] "There is value either way so I don't think it matters".

[IFS] "If we did both but, used the sim for full stall training and taking the upsets through to landing then the plane should be first but, with the training model used currently, they are interchangeable”.

\section{B. Performance analysis and findings from earlier US Navy funded Calspan research}

Prior to this Operational Test, the US Navy sponsored an effort whose purpose was to develop, test, and make recommendations for implementing an Advanced Maneuver \& Upset Recovery Training (AM-URT) program that would meet the unique needs of Naval Patrol aircraft operations (ref. 7). A typical FFS was fitted with an expanded aerodynamic model was used to determine whether aerodynamic models would be a limiting factor. The model was based on a Boeing 737-800 (typical aerodynamic data package) and a U.S. Navy developed P-8A Poseidon model (with expanded aerodynamic data). It was modified and expanded to represent the proper trends and magnitudes of response at high angles of attack to include post-stall characteristics. The IFS aircraft's fly-by-wire flight control system was programmed to represent the characteristics and feel of the P-8A aircraft and was based on the same model.

The two significant challenges in using the FFS for AM-URT were (a) to assure that the FFS approximated the jet upset events sufficiently and (b) that when executed, the maneuvers did not exceed the limits of the aircraft aerodynamic models used to program the simulators. It is important to note that the demands on the training device are inherently different for this type of training due to the magnitude of the maneuvers and the importance of motion cueing. Consequently, US Navy and Calspan flight test and training personnel were used to validate each candidate maneuver by confirming that it remained within the certified envelope and that the FFS adequately represented the aircraft for the purposes of AM-URT.

One important aspect of the upset maneuvers chosen was their applicability beyond the specific events trained. The intent was not to train the pilot to deal with or recover only from specific events and scenarios. The maneuvers chosen were intended only as examples of the multitude of upsets that could be encountered. The broader value of the training maneuvers was to teach pilots how to evaluate a never-before-seen situation and then how to maneuver a large transport airplane back to a safe and stable condition. In the end, the goal was to marry expanded situational awareness, knowledge, and judgment with the requisite 'stick and rudder' skill-sets necessary to successfully master the many flying challenges faced over a career of operational flying.

The AM-URT program that was developed as part of this effort consisted of formal academic training and flight training in either the FFS or the IFS aircraft. In the academics phase, the pilots were given instruction in advanced aerodynamics, causes of jet upset, and introduced to the critical skill-sets necessary for recovery. The flight training 
consisted of a demonstration of the aerodynamic concepts discussed in academics, recovery from unusual attitudes, and jet upset recoveries. The syllabus was identical for both the IFS and FFS training.

Thirty USN operational and test pilots used as research subjects. All were either currently flying the Lockheed P3 Orion or had flown the aircraft operationally for at least one tour. All were at least Aircraft Commander qualified and most were instructor pilots. The pilots were split into three groups for the test - two training (IFS or FFS) and one control (Table 2). For the training group, each pilot was evaluated prior to receiving the training and immediately following. For the control group, the second evaluation occurred after a flight that consisted of basic instrument maneuvers (no AM-URT). A set of standardized evaluation metrics that measured both knowledge and performance was used.

Table 2. Evaluation Order and Training Events.

\begin{tabular}{|c|c|c|c|}
\hline \multirow{2}{*}{ Event } & \multicolumn{3}{|c|}{ Experimental Group } \\
\cline { 2 - 4 } & GP1 - FFS & GP2 - IFS & GP3 - Control \\
\hline \hline 1 & Eval \#1 & Eval \#1 & Eval \#1 \\
\hline 2 & AM-URT (FFS) & AM-URT (IFS) & Inst Man (IFS) \\
\hline 3 & Eval \#2 & Eval \#2 & Eval \#2 \\
\hline 4 & AM-URT (IFS) & & AM-URT (IFS) \\
\hline \hline Pilots/GP & 10 & 10 & 10 \\
\hline
\end{tabular}

Two general categories of maneuvers were evaluated: UAR and Upset Event Recovery [UER] (Table 3). The UAR was a recovery from an unusual attitude defined as a pitch and/or bank angle beyond that normally encountered during operational flight. The maneuver was initiated by the instructor who flew the aircraft to a predetermined initial condition. The pilot being evaluated had eyes closed during the automatic setup maneuver. Once the setup was complete, the pilot was required to recover the aircraft back to straight-and-level. UER maneuvers were defined as maneuvers where some internal failure or external event caused the aircraft to be upset such that the pilot had to adopt a novel control strategy in order to make a successful recovery.

Table 3. IFS Evaluation Events.

\begin{tabular}{|l|l|}
\hline \multicolumn{2}{|l|}{ Evaluation Maneuver Description } \\
\hline $\begin{array}{l}\text { Unusual Attitude } \\
\text { [Nose-Low] }\end{array}$ & $\begin{array}{l}\text { Automatically flown setup to initial condition: } \\
\text { Pitch: - } 20^{\circ} \\
\text { Bank: }+/-90^{\circ}\end{array}$ \\
\hline $\begin{array}{l}\text { UpsetEvent } \\
\text { [Pitch Axis] }\end{array}$ & $\begin{array}{l}\text { Pitch upset implemented like trim runaway (ramp input) to } \\
100 \% \text { max command }\end{array}$ \\
\hline $\begin{array}{l}\text { Upset Event } \\
\text { [Roll Axis] }\end{array}$ & $\begin{array}{l}\text { Roll Moment (step input) to } 100 \% \text { max command like } \\
\text { spoiler jam. Roll control from ailerons remain active }\end{array}$ \\
\hline $\begin{array}{l}\text { UpsetEvent } \\
\text { [Yaw Axis] }\end{array}$ & $\begin{array}{l}\text { Yaw Moment (step input) to 100\% max command. Roll } \\
\text { due to sideslip equivalent to max roll commnad. }\end{array}$ \\
\hline
\end{tabular}

The primary goal of the program was to determine if upset recovery skills, knowledge, and abilities could be successfully learned through AM-URT in a FFS and IFS aircraft. While FFS training did result in a significant improvement in pilot skill, knowledge and confidence, pilots were not able to reach the satisfactory level of proficiency from FFS training alone (fig. 9). The IFS trained group, on the other hand, was able to fully assimilate the maneuver cues and use that information to develop and implement a successful recovery strategy. It should be noted that the academics phase of training improved all the pilots' knowledge of the UER maneuver category due to the unique and novel nature of these recovery techniques and the advanced aerodynamic concepts required for recovery. 


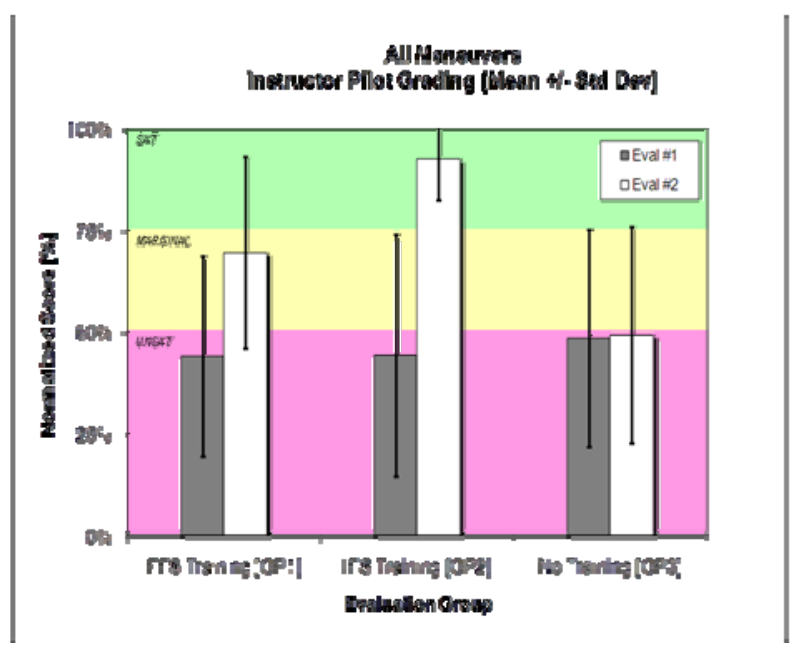

Figure 9. Instructor Pilot Grading - All Maneuvers.

One very interesting finding was the difference between the initial and final scores for UAR versus UER maneuvers. Evaluation results for the pitch UAR and UER are shown in Figures 10 and 11, respectively. Initial evaluation scores for all groups for the UER were all in the unsatisfactory region of performance. In stark contrast, for the UAR evaluation maneuvers, scores were all in the "marginal" region. For the UAR, final scores for the two trained groups (FFS and IFS) were in the satisfactory region of performance. However, for the UER evaluation maneuvers, only the IFS trained group reached satisfactory. These differences were likely due to the more conventional nature of UAR and the fact that all pilots had performed UAR in an airborne environment during their normal pilot training. Furthermore, the fact that the control group showed negligible improvement in UAR scores (no testing effects) further supports the premise that UAR was a pre-existing skill set. The novel nature of the UER techniques (i.e. alternate control strategy, etc.) coupled with the fact that none of the pilots had ever performed such maneuvers in an airborne environment likely contributed to the FFS trained group's inability to apply the techniques learned to improve their scores to the extent that the group trained in the actual airborne environment (IFS Trained) was able to. Consequently, the data support the conclusion that UAR skills are a necessary but not sufficient condition when it comes to recovering from actual upset events. The critical skill set required for a successful recovery includes an alternate control strategy necessary to deal with the upset event itself. A comprehensive AMURT program must include not only training in extreme-attitude-flight, but also in analyzing and correcting the condition that caused it to occur in the first place. In other words, it is not the "attitude", it's the "upset". 


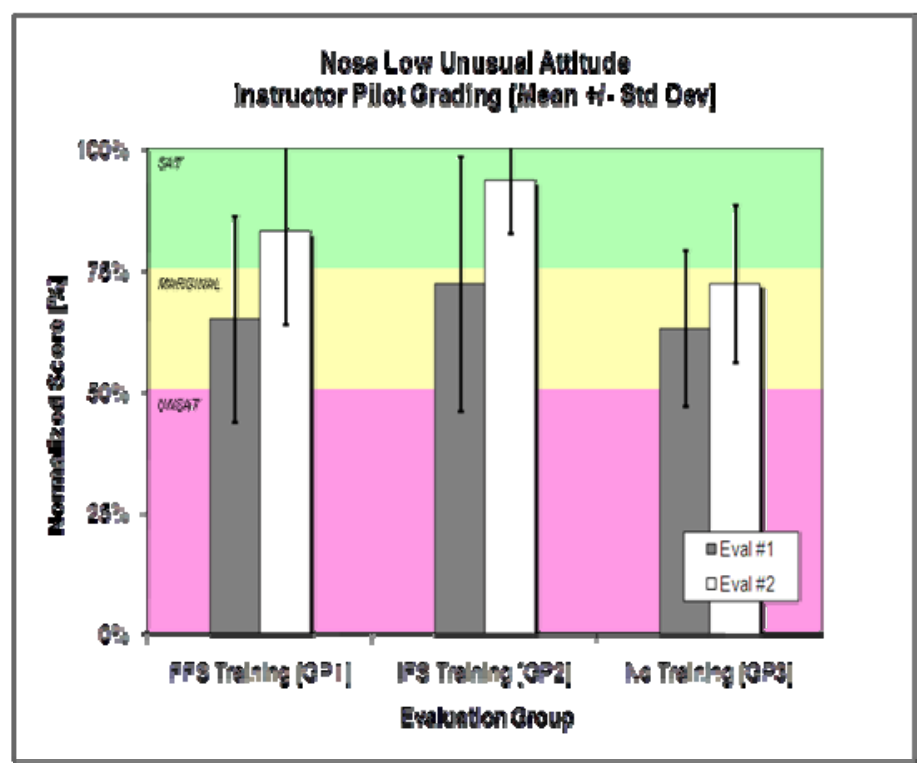

Figure 10. Nose-Low Unusual Attitude Recovery.

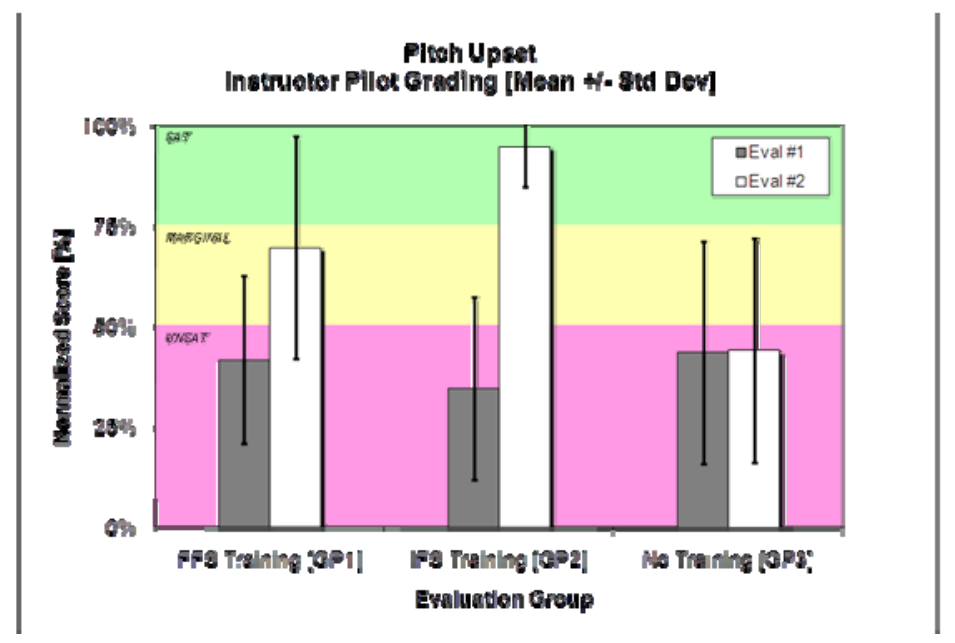

Figure 11. Pitch Upset Recovery.

The expanded aerodynamic envelope used in the FFS was ample for this AM-URT training. No exceedance of the limits of the aerodynamic envelope was noted. However, it is important to recognize that even if the maneuvers remain within the acceptable envelope, the demands put on the FFS are inherently different for this type of training due to the importance of motion cueing. While the aerodynamic modeling may be sufficient, it was recognized that the FFS cannot fully replicate all flight characteristics such as sustained linear and rotational accelerations. This meant that the pilot could not rely on normal sensory feedback that is available in the actual airplane. It was known from other Calspan research in this regime (ref. 8) that an awareness of g-force and structural loading was necessary and critical for any FFS based AM-URT because without this provision, g-force and load limit exceedances could result in aircraft overloading and potentially negative training. Consequently, a Calspan developed Dual Axis Load Meter (DALM) was used for this study. The DALM brings the vital load information to the simulated cockpit and to the pilot, resulting in a more effective training experience.

The DALM design incorporates an easy to read graphical display that provided visual enhancements to fullflight simulation training. The digital display showed instantaneous center-line g-forces. The graphical display represented total g-forces on each wing-half, including both positive and negative forces. The graphics effectively displayed differential wing loading due to rolling. The display also showed lateral loads on the vertical stabilizer, as 
a percentage of maximum. For both axes, graphical display changed color from green to yellow to red as load limits were reached. If limits were exceeded, the graphically displayed load flashed red. The Dual-Axis Load Meter has been shown to be especially effective during training for upset recovery maneuvers requiring elevated g-forces or where asymmetric or an alternate control strategy necessitates asymmetric longitudinal or lateral control inputs. The pilot is immediately alerted of improper techniques resulting in excessive aircraft loads. The pilot learns not to make overly large or aggressive inputs. Representative displays from the DALM are shown below (Figure 12). The display on the left shows an aircraft yaw upset (tail load) where the pilot is pulling g's to recover. The right wing is being overloaded. The display on the right shows the same upset event but in this case, the pilot is unloading.

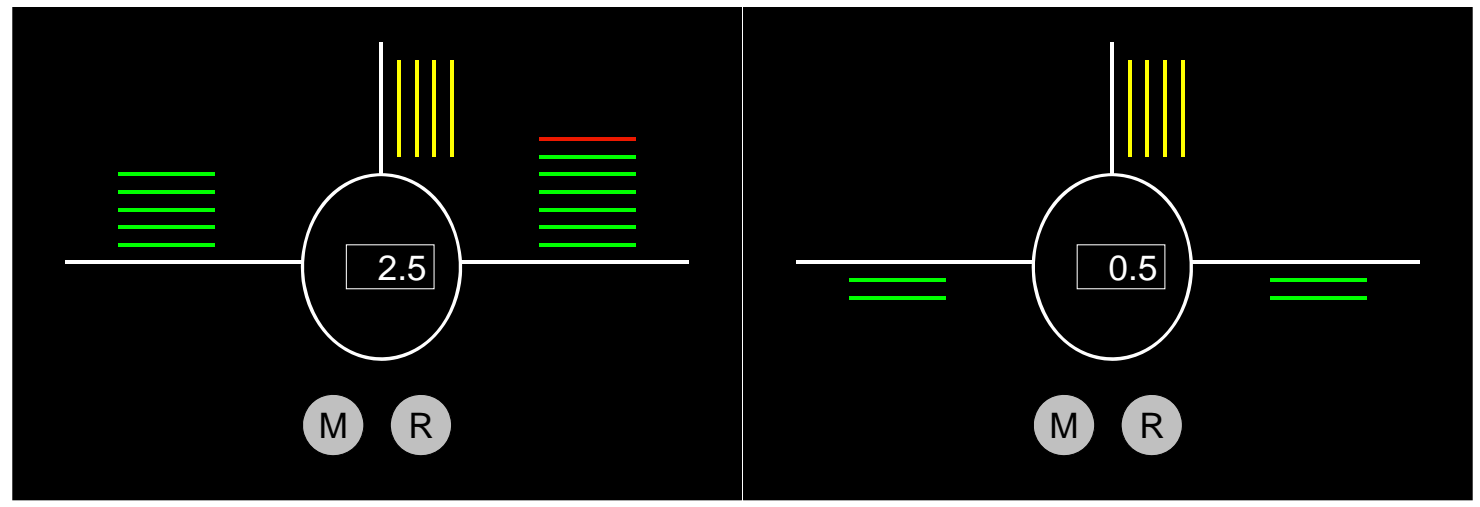

Figure 12. Aircraft Load Display Device.

The DALM was shown to mitigate the cue-deficiency limitation and to enhance the training value of the FFS by providing the trainee with real-time awareness of g's and structural loads. However, the FFS still only provided the look of the maneuvers vice the feel.

\section{Simulation Findings}

The results clearly show that those pilots who received FFS training prior to their IFS training, consistently perform better in their final evaluation than those who did not receive FFS training, and only had one IFS training session. Pilots' performance increased after being provided upset recovery training in an FFS. Effective training can be accomplished in the FFS as long as care is taken to ensure the aerodynamic model accurately portrays the maneuvers to be flown.

Full Flight Simulators have limitations but can be used to provide some aspects of upset recovery training. A FFS will not provide the motion and "g" cues that a pilot must experience in order to develop a frame of reference to allow him or her to diagnose and recover from real-world upsets. Consequently, FFS training alone will not adequately prepare a pilot for the upsets he could experience. Additionally, the following steps must be taken to ensure FFS upset training is effective:

- The planned maneuvers must be evaluated to ensure they do not exceed the flight test and wind tunnel data envelopes. A higher fidelity aerodynamic model will likely be required to ensure this. Additionally, feedback must be provided to the pilot so he knows if he has exceeded a limit, either an aerodynamic model limit or an aircraft limit. Possible forms of feedback include a g-meter and a display at the instructor station showing where the airplane is in the envelope in real-time.

- The FFS should be evaluated subjectively by subject matter experts to ensure it is suitable for upset recovery training.

- The pilots must be clearly briefed on the differences between what they will experience in the FFS and what to expect in an actual aircraft upset situation.

The primary conclusion to the study was that upset recovery skills, knowledge, and abilities can be successfully learned through AM-URT. A good academic foundation is critical as the aerodynamic principles were not well 
known or well understood prior to the training. Furthermore, while FFS training did result in a statistically significant improvement in pilot skill, knowledge and confidence, pilots were not able to reach a satisfactory level of proficiency from FFS training alone. The IFS trained group was able to fully assimilate the maneuver cues and use that information to develop and implement a successful recovery strategy. The optimum upset recovery training program should include all three elements (academics, IFS, and FFS) to provide the pilot with a full understanding of upsets and how to recover.

All the participants made very positive statements on the effectiveness of the course. One particularly noteworthy statement that summed up the positive pilot comments was: "This training was probably the most effective in improving my airmanship in 20 years."

\section{Conclusions and Next Steps}

All data indicators through the US Navy sponsored efforts with NASA Langley Research Center, Calspan Corporation, and Bihrle Applied Research show that great improvements in modeling fidelity can be achieved by expansion of aerodynamic databases beyond what is customary practice with commercial vehicles. Due to the risk of departure from controlled flight as military missions push the envelopes of aircraft that were designed for a fairly benign commercial passenger flight environment, much value can be gained in training the pilots for upset conditions. The use of the best available databases for analytical purposes combined with the advances in simulation cues go far to improving the pilot's situational awareness and understanding the limitations of the vehicles they fly. The ability to accurately model flight in upset conditions and provide in-flight training to represent in-flight cues has shown to be not only beneficial for training, but desired by US Navy pilots.

As the value of the upset recovery training has been established, the US Navy now has options to bring training directly to the P-8A fleet in a phased manner. The academics and computer based training modules are available for implementation into the P-8A training curriculum. The P-8A training simulator has been evaluated for use with a sub-set of upset conditions/scenarios and the simulator training syllabus is being modified. Enhancements to the P8A trainer aerodynamic database are in the planning stages with implementation expected within a year. In-flight simulation has proven to be effective and is available to the P-8A community. Ground based simulation devices with representative models of flight in upset conditions have now been established and are available for use immediately. Enhancements to simulation models are also being pursued to represent battle-damaged aircraft for the purpose of provided realistic training in threat environments.

\section{References}

1 U.S. Navy Small Business Innovative Research, topic number N08-005, 'Innovative Techniques of Modeling and Simulation for Commercial Derivative Aircraft Upset Recovery’.

${ }^{2}$ Foster, John V., et al., "Dynamics Modeling and Simulation of Large Transport Airplanes in Upset Conditions," AIAA2005-5933.

${ }^{3}$ Wilborn, James E., and Foster, John V., "Defining Commercial Transport Loss-of-Control: A Quantitative Approach," AIAA-2004-4811.

${ }^{4}$ Cunningham, Kevin, et al., "Simulation Study of a Commercial Transport Airplane During Stall and Post-Stall Flight," SAE Technical Paper Series 2004-01-3100.

${ }^{5}$ Shah, Gautam H., et al., "Wind-Tunnel Investigation of Commercial Transport Aircraft Aerodynamics at Extreme Flight Conditions," SAE Technical Paper Series 2002-01-2912.

${ }^{6}$ Bihrle Applied Research, Inc.; “Total Envelope Modeling Application for Transport Aircraft”, SBIR N08-005, Phase II Report, June, 2012.

${ }^{7}$ Belcher, Michael F. and Luallen, Terry M.; Advanced Maneuver and Upset Recovery Training (AM-URT), Master Report, 5 April 2011. 
${ }^{8}$ Knotts, L.H., Moreau, R., Priest, J. E., Joint Development and Testing of Integrated FFS-IFS AM-URT Program and HUDEFVS Upset Recovery Display Format for Transport Aircraft. Proceedings of the Society of Experimental Test Pilots Seminar, San Diego, CA, March 2008 